\title{
Rancang Bangun Prototipe Sistem Peringatan Jarak Aman pada Kendaraan Roda Empat Berbasis Mikrokontroler ATMEGA32
}

\author{
Rina Mardiati, Ferlin Ashadi, Geusan Farid Sugihara \\ Jurusan Teknik Elektro, Fakultas Sains dan Teknologi, Universitas Islam Negri Sunan Gunung Djati \\ Jl. A.H Nasution No. 105 Bandung \\ e-mail: r_mardiati@uinsgd.ac.id,fe_ash@yahoo.com, geusanfaridsugihara@gmail.com,
}

\begin{abstract}
Abstrak - Peningkatan jumlah kendaraan menyebabkan jalan raya menjadi semakin padat dan menimbulkan tingginya resiko kecelakaan lalulintas, ini merujuk pada data statistik dari Badan Pusat Statistik (BPS) daerah Jawa Barat. Peningkatan angka kecelakaan yang cukup tinggi ini disebabkan oleh faktor-faktor kesalahan atau kelalaian pengemudi (human error), sistem pada kendaraan dan faktor jalan. Oleh karena itu, dibutuhkan sebuah solusi yang dapat membantu mengurangi angka kecelakaan pada pengguna kendaraan khususnya kendaraan roda empat. Dengan menggunakan sensor ultrasonik berbasis mikrokontroler ATMEGA32 diharapkan menjadi sebuah sistem yang dapat membantu mengurangi angka kecelakaan khususnya pada kendaraan roda empat. Pada penelitian ini digunakan metode Action Research yaitu dengan melalui beberapa tahapan seperti data dan pengumpulan data, analisis kebutuhan, perancangan, implementasi, dan pengujian alat. Sistem ini memiliki cara kerja dengan memberikan suatu peringatan berupa bunyi dan tampilan ukuran jarak yang ditujukan untuk pengemudi kendaraan roda empat. Keluaran sistem dibuat melalui program yang disesuaikan dengan kebutuhan jarak aman seperti pada LCD mulai dari jarak $300 \mathrm{~cm}$ hingga $200 \mathrm{~cm}$ menampilkan "HATIHATI", dan $200 \mathrm{~cm}$ hingga $0 \mathrm{~cm}$ menampilkan "BERBAHAYA". Pada buzzer mulai dari jarak 300 hingga $200 \mathrm{~cm}$ berbunyi satu kali dengan tempo yang lambat secara berulang, 200 hingga $150 \mathrm{~cm}$ berbunyi dua kali dengan tempo lambat secara berulang, 150 hingga $100 \mathrm{~cm}$ berbunyi dua kali dengan tempo sedang secara berulang, 100 hingga $50 \mathrm{~cm}$ berbunyi dua kali dengan cepat secara berulang, 50 hingga $10 \mathrm{~cm}$ berbunyi dua kali dengan tempo lebih cepat secara berulang, 10 hingga $0 \mathrm{~cm}$ berbunyi panjang satu kali secara berulang. Pada saat pengujian alat telah dilakukan pada kendaraan dapat disimpulkan bahwa alat bekerja sesuai dengan program yang dibuat dan alat dapat bekerja secara optimal ketika kendaraan roda empat berjalan pada laju kecepatan maksimum $50 \mathrm{~km} / \mathrm{jam}$.
\end{abstract}

Kata Kunci: jarak aman, kendaraan roda empat, mikrokontroler ATMEGA32, sensor ultrasonic.

\section{Pendahuluan}

Pada era globalisai saat ini perkembangan dalam ilmu pengetahuan dan teknologi (IPTEK) yang begitu pesat banyak membawa perubahan pada segala aspek, terutama perkembangan pada industri otomotif khususnya dalam industri mobilisasi. Perkembangan ini dipengaruhi oleh tingginya kebutuhan masyarakat terhadap penggunaan kendaraan roda empat. Tingginya jumlah penggunaan kendaraan roda empat oleh masyarakat mengakibatkan jalan raya menjadi semakin padat, ini didasari data Badan Pusat Statistik (BPS) daerah Jawa Barat tahun 2011[5]. Dari kepadatan ini pengemudi menjadi terganggu konsentrasinya dan pengambilan keputusan menjadi kurang tepat (human error), inilah salah satu faktor yang menjadi penyebab kecelakaan. Menimbang berdasarkan data yang ada, maka diperlukan sebuah sistem yang diharapkan dapat membantu mengurangi angka kecelakaan pada kendaraan roda empat.

Permasalahan yang ada dijadikan tujuan pada penelitian ini yaitu dengan membuat suatu "rancang bangun prototipe sistem peringatan jarak aman pada kendaraan roda empat berbasis

TELKA, Vol.2, No.1, Mei 2016, pp. 53 61

ISSN: 2502-1982 
mikrokontroler ATMEGA32" sebagai sistem peringatan jarak aman antara kendaraan roda empat yang dikendarai dengan kendaraan lain atau hambatan yang berada tepat didepanya. Penelitian yang dilakukan dengan menggunakan metode Action Research yaitu penelitian yang dilakukan secara berkelanjutan.

Berdasarkan permasalahan dan tujuan penelitian dalam merancang dan membangun sistem peringatan jarak aman ini dibatasi oleh sejumlah hal yaitu sistem yang dibuat menggunakan mikrokontroler ATMEGA32 sebagai pemroses logika program yang dibuat, sensor ultrasonik digunakan untuk mengukur jarak dari 0 hingga $300 \mathrm{~cm}$, buzzer digunakan sebagai peringatan bunyi penanda jarak Pada buzzer mulai dari jarak 300 hingga $200 \mathrm{~cm}$ berbunyi satu kali dengan tempo yang lambat secara berulang, 200 hingga $150 \mathrm{~cm}$ berbunyi dua kali dengan tempo lambat secara berulang, 150 hingga $100 \mathrm{~cm}$ berbunyi dua kali dengan tempo sedang secara berulang, 100 hingga $50 \mathrm{~cm}$ berbunyi dua kali dengan cepat secara berulang, 50 hingga $10 \mathrm{~cm}$ berbunyi dua kali dengan tempo lebih cepat secara berulang, 10 hingga $0 \mathrm{~cm}$ berbunyi panjang satu kali secara berulang. Pada saat pengujian alat telah dilakukan pada kendaraan dapat disimpulkan bahwa alat bekerja sesuai dengan program, dan LCD digunakan sebagai tampilan jarak mulai dari jarak $300 \mathrm{~cm}$ hingga $200 \mathrm{~cm}$ menampilkan "HATI-HATI", dan $200 \mathrm{~cm}$ hingga $0 \mathrm{~cm}$ menampilkan "BERBAHAYA".. Perancangan sistem menggunakan software ISIS Profesional Proteus dan Eagle 6.3.0 Light. Untuk pembuatan program menggunakan Code Vision AVR, avrdude-GUI digunakan sebagai driver penghubung dan Downloader sebagai perangkat penghubung.

\section{Tinjauan Pustaka}

\subsection{Mikrokontroler}

Mikrokontroler adalah komponen elektronika yang didalamnya terkandung sistem interkoneksi antara mikroprosesor, RAM, ROM, I/O interface, dan beberapa peripheral. Mikrokontroler disebut juga On-chip-Peripheral. Mikrokontroller ATMEGA32 adalah mikrokontroler yang diproduksi oleh Atmel. mikrokontroler ini memiliki clock dan kerjanya tinggi sampai $16 \mathrm{MHz}$, ukuran flash memorinya cukup besar, kapasistas SRAM sebesar $2 \mathrm{~Kb}$, 32 buah port I/O yang sangat memadai untuk berinteraksi dengan $L C D$.

\subsection{Sensor Ultrasonic}

Parallax PING ultrasonic merupakan sebuah sensor pengukur jarak tanpa kontak langsung, dengan kemampuan jarak ukur $2 \mathrm{~cm}$ (0.8 inches) sampai $3 \mathrm{~m}$ (3.3 yards) di udara yang memiliki cepat rambat $343 \mathrm{~m} / \mathrm{s}$. Sensor ini mempunyai 3 pin yang memiliki fungsi sepert pin I/O untuk pengontrolan mikrokontroler, pin Vdd untuk catu daya sebesar 5volt, dan pin Vss yaitu Ground. Sensor ini bekerja berdasarkan prinsip pantulan gelombang suara, dimana sensor akan memancarkan gelombang suara yang kemudian menangkap pantulannya kembali dengan perbedaan waktu sebagai dasar penginderaannya. Perbedaan waktu antara gelombang suara dipancarkan dengan ditangkapnya kembali gelombang suara tersebut adalah berbanding lurus dengan jarak atau tinggi objek yang memantulkannya. Jenis objek yang dapat diindera diantaranya adalah: objek padat, cair, butiran maupun tekstil.

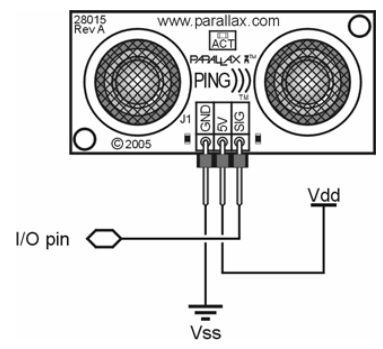

Gambar 1. Sensor parallax ping 


\subsection{Buzzer}

Buzzer adalah sebuah komponen elektronika yang berfungsi untuk mengubah getaran listrik menjadi getaran suara. Pada dasarnya prinsip kerja buzzer hampir sama dengan loud speaker, jadi buzzer juga terdiri dari kumparan yang terpasang pada diafragma dan kemudian kumparan tersebut dialiri arus sehingga menjadi elektromagnet, kumparan tadi akan tertarik ke dalam atau keluar, tergantung dari arah arus dan polaritas magnetnya, karena kumparan dipasang pada diafragma maka setiap gerakan kumparan akan menggerakkan diafragma secara bolak-balik sehingga membuat udara bergetar yang akan menghasilkan suara. Buzzer biasa digunakan sebagai indikator bahwa proses telah selesai atau terjadi suatu kesalahan pada sebuah alat (alarm).

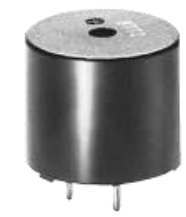

Gambar 2. Buzzer

\subsection{LCD (Liquid Crystal Display)}

LCD (Liquid Crystal Display) atau dapat di bahasa Indonesia-kan sebagai "Tampilan Kristal Cair" adalah suatu jenis media tampilan yang menggunakan kristal cair sebagai penampil utama. $L C D$ bisa memunculkan gambar atau tulisan dikarenakan terdapat banyak sekali titik cahaya (piksel) yang terdiri dari satu buah kristal cair sebagai sebuah titik cahaya. Walau disebut sebagai titik cahaya, namun kristal cair ini tidak memancarkan cahaya sendiri. Sumber cahaya di dalam sebuah perangkat $L C D$ adalah lampu neon berwarna putih dibagian belakang susunan kristal cair. Titik cahaya yang jumlahnya puluhan ribu bahkan jutaan inilah yang membentuk tampilan citra. Kutub kristal cair yang dilewati arus listrik akan berubah karena pengaruh polarisasi medan magnetik yang timbul dan oleh karenanya akan hanya membiarkan beberapa warna diteruskan sedangkan warna lainnya tersaring.

\subsection{Bahasa C}

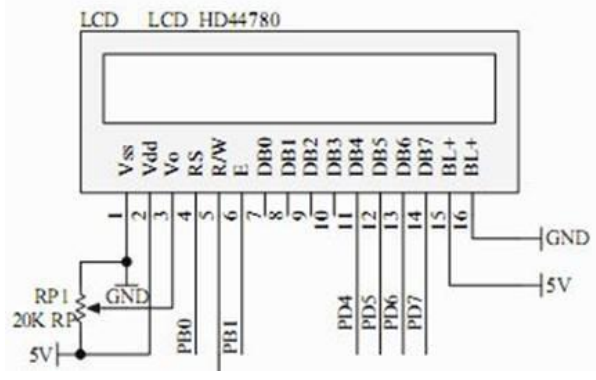

Gambar 3. Jalur pada LCD

Bahasa C adalah bahasa pemrograman yang sudah dikembangkan sejak tahun 1972 oleh Dennis Ritchie seorang ahli dari Bell Telephone Laboratories untuk digunakan pada sistem operasi Unix. Walaupun bahasa $\mathrm{C}$ dirancang untuk mengimplementasikan perangkat lunak dari suatu sistem seperti sistem operasi, bahasa $\mathrm{C}$ juga sering digunakan pada aplikasi perangkat lunak portable [DMR88].

Bahasa $\mathrm{C}$ adalah sebuah bahasa penerapan sistem yang imperatif (prosedural) yang dirancang agar dapat dikompilasi dengan relatively straightforward compiler, agar dapat memberikan akses tingkat rendah langsung kepada memori, sehingga bahasa $\mathrm{C}$ dapat membangun instruksi langsung kepada mesin dengan dukungan run-time minimum. Karena penggunaan bahasa tingkat rendah iniliah bahasa $\mathrm{C}$ menjadi pendorong pemrograman crossplatform karena bahasa $\mathrm{C}$ memiliki standar sehingga sebuah program $\mathrm{C}$ yang sudah tercompile secara standar, dapat dikompilasi ke berbagai platform yang sangat luas dengan berbagai sistem 
operasi dengan sedikit ataupun tanpa perubahan pada source code program tersebut. Bahasa $\mathrm{C}$ banyak digunakan pada berbagai platform seperti mikrokontroler dan supercomputer [4].

\section{Metodologi Penelitian}

Dalam penelitian "Rancang Bangun Prototipe Sistem Peringatan Jarak Aman pada Kendaraan Roda Empat Berbasis Mikrokontroler ATMEGA32" digunakan metode Action Research. Yaitu sebuah penilitian yang dilakukan dengan cara mengumpulkan beberapa referensi yang berkaitan, menganalisis kebutuhan dalam pembuatan alat, merancang dan membangun alat, kemudian melakukan pengujian dan menganalisis hingga mendapatkan hasil yang memenuhi kebutuhan pengemudi. Bagan metode dapat dilihat pada gambar 4 .

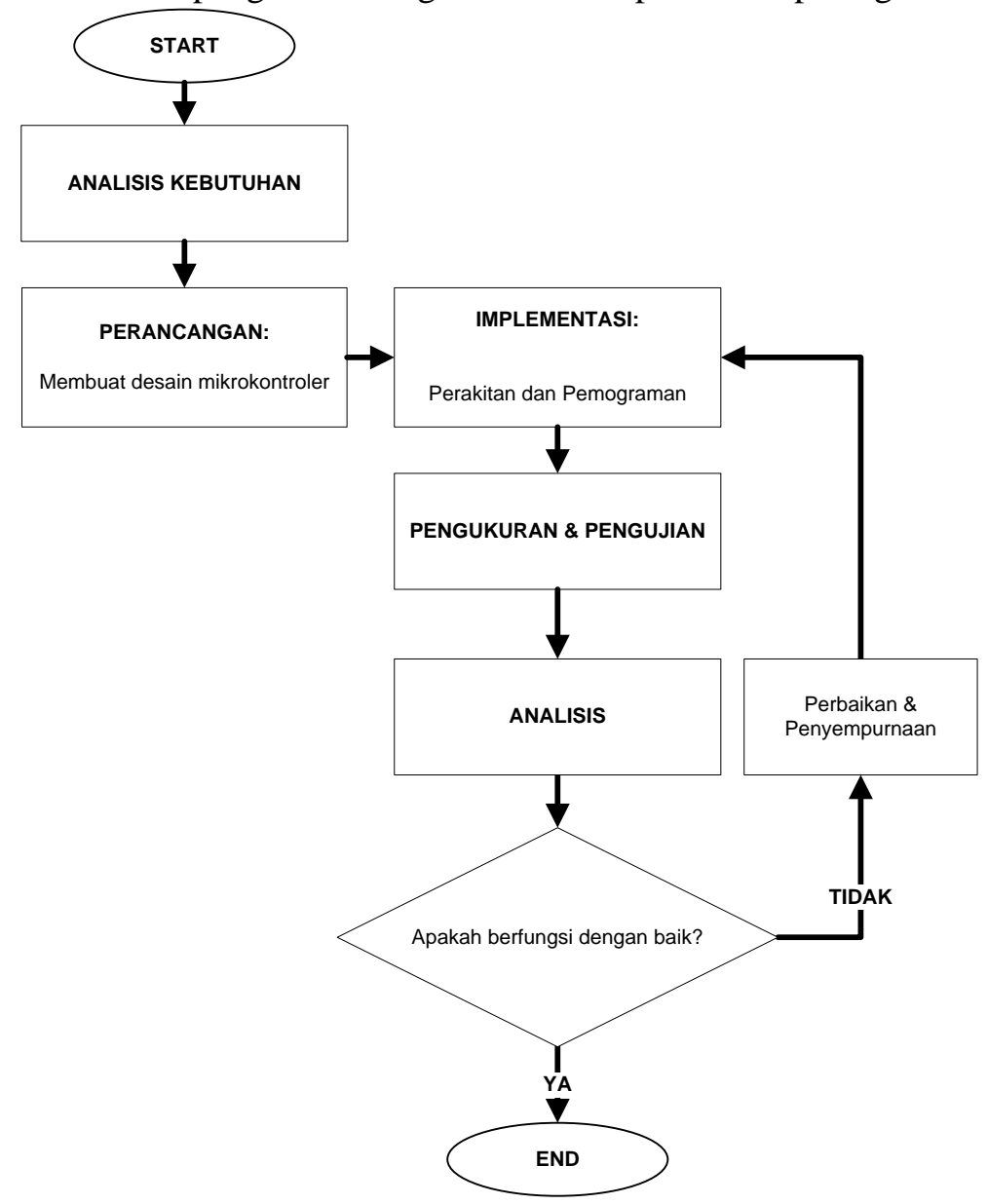

Gambar 4. Diagram metodologi penelitian

Pada tahap perancangan terdapat beberapa point penting yang akan dikerjakan, yaitu membuat desain rangkaian mikrokontroler dengan menggunakan Software Proteus dan Eagle 6.3.0 Light. Pada tahap ini terdapat alur kerja dari alat yang akan menjelaskan cara kerja alat yang akan dibuat. Dapat dilihat pada Gambar 5 berikut. 


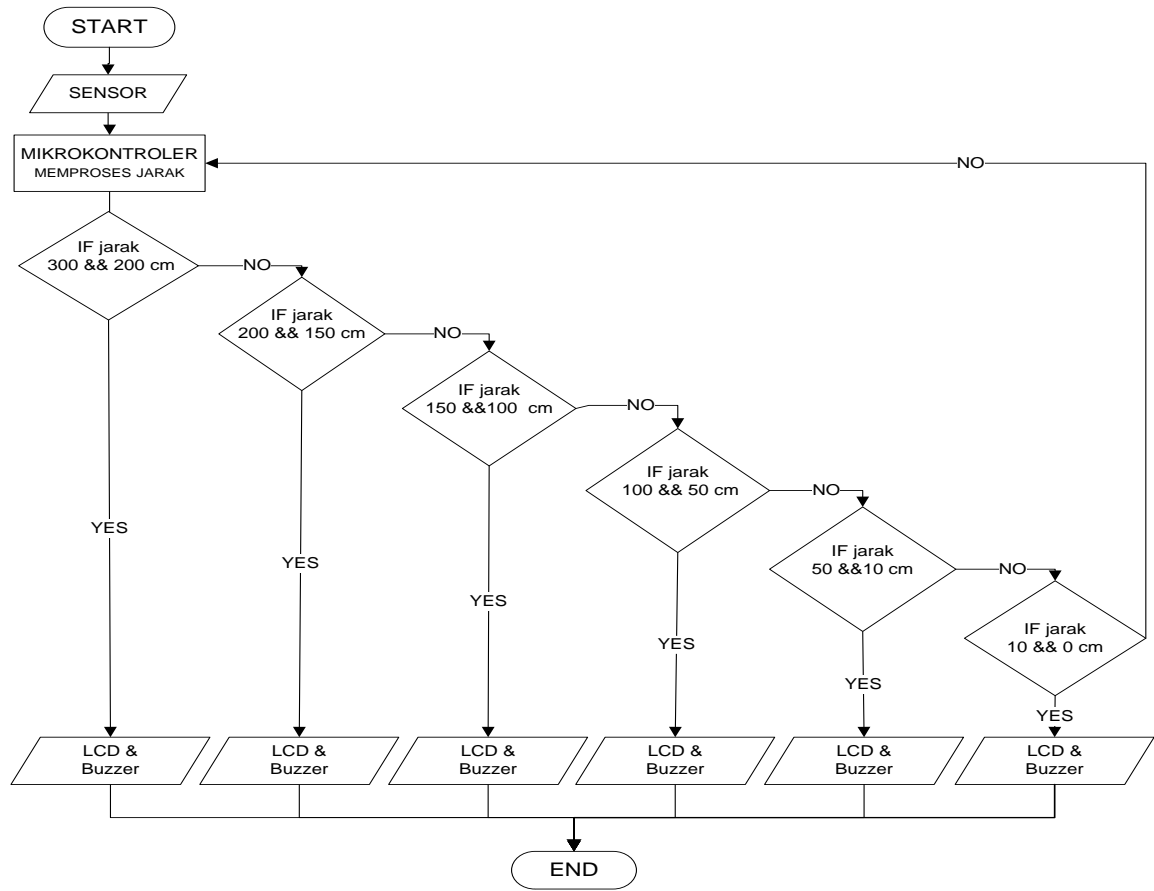

Gambar 5. Alur kerja alat

Terdapat dua tahapan penting yang harus dikerjakan dalam pembuatan alat, yaitu: perakitan Hardware (Perangkat Keras) dan Coding (Pemograman). Pada tahap pengujian, dilakukan dengan cara menganalisis respon sistem agar dapat disesuaikan dengan input program. Hasil pengujian kemudian dibandingkan dengan identifikasi masalah yang dijabarkan apakah berfungsi dengan baik atau tidak. Beberapa macam hal yang akan diuji dan dianalisis, yaitu: Mikrokontroler, Sensor Ultrasonic, LCD dan Buzzer.

\section{Perancangan dan Implementasi}

\subsection{Perancangan}

Pada tahap ini dilakukan pembuatan desain rangkaian mikrokontroler dengan menggunakan software ISIS Profesional Proteus dan Eagle 6.3.0 Light. Pada desain rangkaian mikrokontroler yang dibuat, digunakan IC ATMEGA32 sebagai inti proses logika. Mikrokontroler IC ATMEGA32 memiliki 40 pin yang dibagi menjadi beberapa PORT yaitu PORT A, B, C, dan D. Dari masing-masing PORT yang ada digunakan sebagai berikut.

1. PORT A digunakan untuk sensor Ultrasonic Ping Parallax.

2. PORT B digunakan untuk menginput program.

3. PORT C digunakan untuk $L C D$.

4. PORT D digunakan untuk Buzzer.

Desain rangkaian mikrokontroler dapat dilihat pada Gambar 6 dibawah ini: 


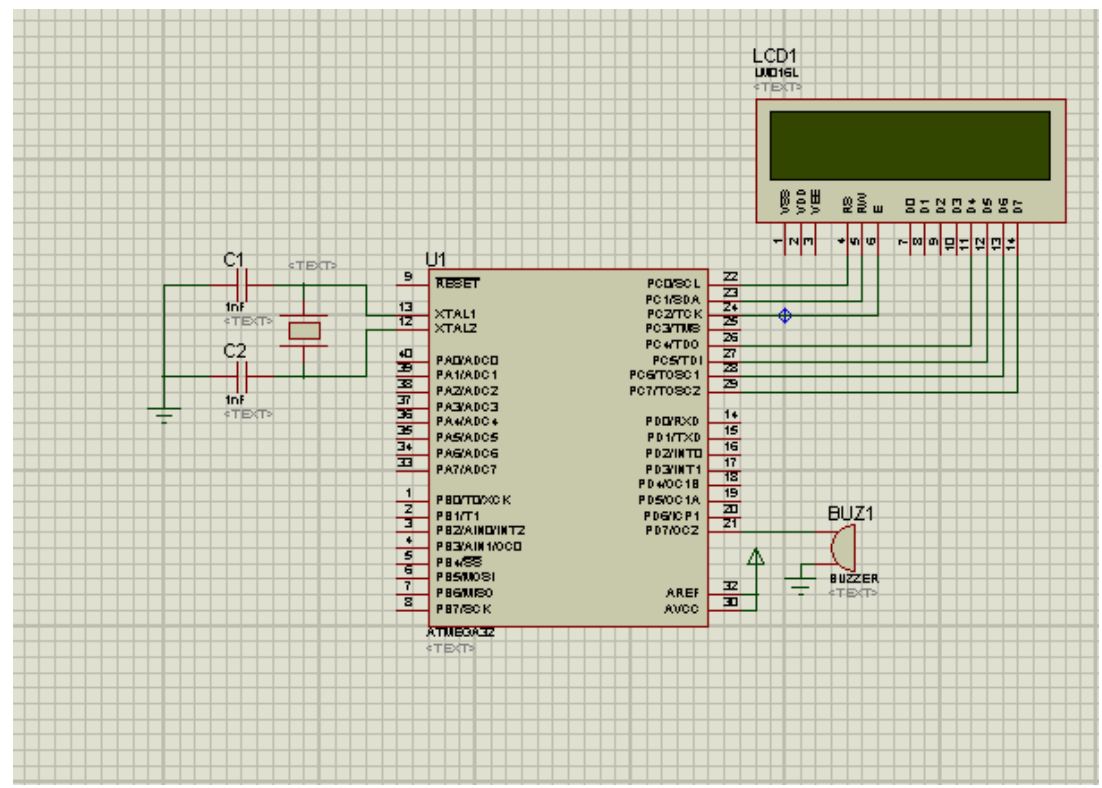

Gambar 6. Desain rangkaian mikrokontroler

Kemudian desain rangkaian dibuat menjadi board rangkaian agar siap dicetak dapat dilihat Gambar 7 dibawah ini.

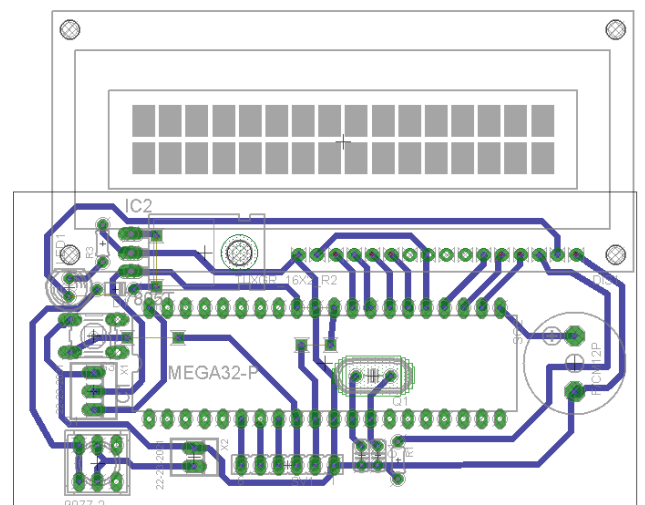

Gambar 7. Desain rangkaian mikrokontroler siap cetak

\subsection{Implementasi}

Pada tahap ini dilakukan perakitan alat hingga pemograman pada alat seperti yang dijabarkan sebagai berikut:

1. Perakitan Hardware (perangkat keras)

a. Mencetak board rangkaian mikrokontroler

b. Pemasangan komponen-komponen pada board rangkaian mikrokontroler

c. Menghubungkan modul sensor ultrasonik pada mikrokontroler

d. Memasangkan buzzer pada rangkaian mikrokontroler

e. Memasangkan LCD pada rangkaian mikrokontroler

2. Coding (pemograman)

Program yang dibuat untuk mikrokontroler menggunakan bahasa "C". Program ini dibuat pada software "Code Vision AVR". Pemograman yang dibuat dengan tujuan agar mengasilkan keluaran seperti berikut:

1. Buzzer menghasilkan bunyi berbeda dimulai dari:

a. 300 hingga $200 \mathrm{~cm}$ berbunyi satu kali dengan tempo yang lambat secara berulang. 
b. 200 hingga $150 \mathrm{~cm}$ berbunyi dua kali dengan tempo lambat secara berulang.

c. 150 hingga $100 \mathrm{~cm}$ berbunyi dua kali dengan tempo sedang secara berulang.

d. 100 hingga $50 \mathrm{~cm}$ berbunyi dua kali dengan cepat secara berulang.

e. 50 hingga $10 \mathrm{~cm}$ berbunyi dua kali dengan tempo lebih cepat secara berulang.

f. 10 hingga $0 \mathrm{~cm}$ berbunyi panjang satu kali secara berulang.

2. Sistem menggunakan $L C D$ untuk menampilkan ukuran jarak dalam satuan sentimeter, yaitu dari $0 \mathrm{~cm}-300 \mathrm{~cm}$.

a. 300 hingga $200 \mathrm{~cm}$ menampilkan "HATI-HATI".

b. 200 hingga $0 \mathrm{~cm}$ menampilkan "BERBAHAYA".

\section{Pengujian dan Analisis}

\subsection{Pengujian Pembacaan Sensor Ultrasonic}

Pada tahap ini dilakukan pengujian antara pembacaan sensor ultrasonik terhadap ukuran jarak yang sebenarnya dengan menggunakan (Meter Ukur) yang sesuai dengan standar. Tujuannya agar dapat mengetahui apakah ada selisih antara hasil pembacaan sensor ultrasonik dengan ukuran sebenarnya. Hasil yang didapat dapat dilihat pada Tabel 1 sebagai berikut:

Tabel 1. Pengukuran Error

\begin{tabular}{|c|c|c|}
\hline $\begin{array}{c}\text { Nilai } \\
\text { Acuan } \\
(\mathbf{c m})\end{array}$ & $\begin{array}{c}\text { Pengukura } \\
\text { Sensor } \\
(\mathbf{c m})\end{array}$ & $\begin{array}{c}\text { Tingkat } \\
\text { Kesalahan } \\
(\mathbf{\%})\end{array}$ \\
\hline 30 & 33 & 10 \\
\hline 60 & 65 & 8,3 \\
\hline 90 & 98 & 8,8 \\
\hline 120 & 130 & 8,3 \\
\hline 150 & 162 & 8 \\
\hline 180 & 195 & 8,3 \\
\hline 210 & 228 & 8,5 \\
\hline 240 & 260 & 8,3 \\
\hline 270 & 293 & 8,5 \\
\hline 300 & 326 & 8,6 \\
\hline & Rata-rata & $\mathbf{0 , 8 5 6}(\mathbf{\%})$ \\
\hline
\end{tabular}

Setelah dilakukan pengujian, terdapat selisih antara ukuran pembacaan sensor ultrasonik dengan ukuran yang sebenarnya seperti pada tabel diatas. Maka dari itu diperlukan pengkalibrasian pada sensor ultrasonik agar ukuran yang didapat sensor ultrasonik menjadi setara dengan ukuran sesuai standar (Meter Ukur).

1. Kalibrasi

Pada tahap kalibrasi ini dilakukan dengan cara seperti berikut.

a. Ketika sensor ultrasonik masih memiliki selisih kemudian sensor ultrasonik disimpan sejajar dengan (meter ukur) yang sesuai ukuran standar pada ukuran $300 \mathrm{~cm}$.

b. Menghitung waktu pengiriman dan penerimaan sinyal suara dari sensor ultrasonik yang ditampilkan pada $L C D$ hingga mendapatkan hasil yang akurat.

c. Setelah diamati didapatkan hasilnya sebesar $1868 \mu$ s.

d. Ukuran jarak $300 \mathrm{~cm}$ yang ditunjukkan meter ukur dibagi dengan waktu yang didapatkan sebesar $1868 \mu \mathrm{s}$, kemudian hasilnya dikalikan 2 sebagai waktu pengiriman dan penerimaan.

e. Lalu hasil yang telah dihitung dimasukkan kedalam program sebagai intruksi yang telah dikalibrasi untuk pengukuran jarak pada sensor agar ukuran jarak lebih akurat.

f. Terakhir alat diuji coba, kemudian didapatkan hasil seperti yang ditunjukkan dalam Tabel 2 dibawah ini. 
Tabel 2. Hasil pengukuran kalibrasi

\begin{tabular}{|c|c|}
\hline $\begin{array}{l}\text { Nilai Acuan } \\
(\mathbf{c m})\end{array}$ & Pengukuran Sensor (cm) \\
\hline 30 & 30 \\
\hline 60 & 60 \\
\hline 90 & 90 \\
\hline 120 & 120 \\
\hline 150 & 150 \\
\hline 180 & 180 \\
\hline 210 & 210 \\
\hline 240 & 240 \\
\hline 270 & 270 \\
\hline 300 & 300 \\
\hline
\end{tabular}

Setelah dilakukan pengkalibrasian dapat terlihat seperti pada tabel diatas bahwa pembacaan ukuran jarak oleh sensor sesuai dengan (Meter Ukur) yang digunakan.

Tabel 3. Hasil Pengukuran Empat Media

\begin{tabular}{|c|c|c|c|c|}
\hline $\begin{array}{c}\text { Pengukuran } \\
\text { sensor } \\
(\mathbf{c m})\end{array}$ & $\begin{array}{c}\text { Hasil } \\
\text { Pengukuran } \\
\text { Media Kayu } \\
(\mathbf{c m})\end{array}$ & $\begin{array}{c}\text { Hasil } \\
\text { Pengukuran } \\
\text { Media Plat } \\
(\mathbf{c m})\end{array}$ & $\begin{array}{c}\text { Hasil } \\
\text { Pengukuran } \\
\text { Media Plastik } \\
(\mathbf{c m})\end{array}$ & $\begin{array}{c}\text { Hasil } \\
\text { Pengukuran } \\
\text { Media Tembok } \\
(\mathbf{c m})\end{array}$ \\
\hline 30 & 30 & 30 & 30 & 30 \\
\hline 60 & 60 & 60 & 60 & 60 \\
\hline 90 & 90 & 90 & 90 & 90 \\
\hline 120 & 120 & 120 & 120 & 120 \\
\hline 150 & 150 & 150 & 150 & 150 \\
\hline 180 & 180 & 180 & 180 & 180 \\
\hline 210 & 210 & 210 & 210 & 210 \\
\hline 240 & 240 & 240 & 240 & 240 \\
\hline 270 & 270 & 270 & 270 & 270 \\
\hline 300 & 300 & 300 & 300 & 300 \\
\hline
\end{tabular}

\subsection{Pengujian Pada Kendaraan Roda Empat}

Pada saat setelah dilakukan pengujian alat pada kendaraan roda empat didapatkan hasil seperti berikut.

a. Mikrokontroler memberikan keluaran pada buzzer dan $L C D$ sesuai dengan program yang diinput seperti:

1. Jarak 300 hingga $200 \mathrm{~cm}$ buzzer berbunyi satu kali dengan tempo yang lambat secara berulang dan $L C D$ menampilkan "HATI-HATI".

2. Jarak 200 hingga $150 \mathrm{~cm}$ buzzer berbunyi dua kali dengan tempo lambat secara berulang dan $L C D$ menampilkan "BERBAHAYA".

3. Jarak 150 hingga $100 \mathrm{~cm}$ buzzer berbunyi dua kali dengan tempo sedang secara berulang dan $L C D$ menampilkan "BERBAHAYA".

4. Jarak 100 hingga $50 \mathrm{~cm}$ buzzer berbunyi dua kali dengan cepat secara berulang dan $L C D$ menampilkan "BERBAHAYA". 
5. Jarak 50 hingga $10 \mathrm{~cm}$ buzzer berbunyi dua kali dengan tempo lebih cepat secara berulang dan LCD menampilkan "BERBAHAYA".

6. Jarak 10 hingga $0 \mathrm{~cm}$ buzzer berbunyi panjang satu kali secara berulang dan $L C D$ menampilkan "BERBAHAYA".

b. Sistem dapat digunakan pada laju kecepatan maksimum $50 \mathrm{~km} / \mathrm{jam}$. Ini disesuaikan dengan kemampuan pembacaan sensor ultrasonik yang hanya dapat mengukur jarak dari 2 hingga $300 \mathrm{~cm}$. Pada saat pengujian diarsipkan kedalam bentuk video dan gambar.

\section{Kesimpulan dan Saran}

\subsection{Kesimpulan}

Setelah pengujian dan analisis dilakukan dapat disimpulkan sebagai berikut.

1. Mikrokontroler memberikan keluaran pada buzzer dan $L C D$ sesuai dengan program yang diinput seperti:

a. Jarak 300 hingga $200 \mathrm{~cm}$ buzzer berbunyi satu kali dengan tempo yang lambat secara berulang dan $L C D$ menampilkan "HATI-HATI".

b. Jarak 200 hingga $150 \mathrm{~cm}$ buzzer berbunyi dua kali dengan tempo lambat secara berulang dan $L C D$ menampilkan "BERBAHAYA".

c. Jarak 150 hingga $100 \mathrm{~cm}$ buzzer berbunyi dua kali dengan tempo sedang secara berulang dan $L C D$ menampilkan "BERBAHAYA".

d. Jarak 100 hingga $50 \mathrm{~cm}$ buzzer berbunyi dua kali dengan cepat secara berulang dan $L C D$ menampilkan "BERBAHAYA".

e. Jarak 50 hingga $10 \mathrm{~cm}$ buzzer berbunyi dua kali dengan tempo lebih cepat secara berulang dan $L C D$ menampilkan "BERBAHAYA".

f. Jarak 10 hingga $0 \mathrm{~cm}$ buzzer berbunyi panjang satu kali secara berulang dan $L C D$ menampilkan "BERBAHAYA".

2. Sistem yang dibuat hanya dapat digunakan pada kendaraan roda empat berjalan dengan laju kecepatan maksimum $50 \mathrm{~km} / \mathrm{jam}$. Ini disesuaikan dengan kemampuan pembacaan sensor ultrasonik yang hanya dapat mengukur jarak dari 2 hingga $300 \mathrm{~cm}$.

\subsection{Saran}

Jika pembaca ingin mengembangkan atau lebih menyempurnakan dari hasil penelitian ini, maka penulis menyarankan seperti:

1. Menggunakan sensor ultrasonik yang memiliki pembacaan mulai dari $0 \mathrm{~cm}$ hingga $600 \mathrm{~cm}$.

2. Menggunakan $L C D$ berukuran 40 kolom $\times 4$ baris yang dapat lebih menunjang kenyamanan kontrol tampilan ukuran jarak pengemudi kendaraan roda empat.

\section{Daftar Pustaka}

[1] Defi, Riana Mahadji Putri. 2009. "Prototipe Pemodelan Parking Assistant Menggunakan Sensor Jarak Pada Kendaraan Roda Empat". Artikel Penelitian. Fakultas Elektro Jurusan Teknik Elektro Universitas Negeri Semarang.

[2] Dwi, Febrika Ambarwati. 2012. "Perancangan Prototipe Pendeteksi Jarak Aman Pada Mobil Berjalan Menggunakan Sensor Ultrasonik Berbasis Mikrokontroler ATMEGA8”. Proyek Akhir Diploma, Bandung. Fakultas Elektro dan Komunikasi, Institut Teknologi Telkom.

[3] Wahyana, Budi dan Maulana Robert. 2011. "Rancang Bangun Sistem Peringatan Parkir Kendaraan Bermotor Roda Empat Menggunakan Suara Dan Sensor Jarak Ping”. Naskah Publikasi, Yogyakarta. Jurusan Teknik Informatika, Sekolah Tinggi Manajemen Informatika Dan komputer Amikom.

[4] Wirdasari Dian. 2010. "Membuat Program Dengan Menggunakan Bahasa C". Jurnal SAINTIKOM, STMIK Trigunadharma.

[5] http://jabar.bps.go.id/publikasi BPS/transportasi2012.pdf 